\title{
Nutrition of Honduran mothers/caretakers
}

\author{
Penelope Nestel, ${ }^{1}$ Alejandro Mellara, ${ }^{2}$ Jorge Rosado, ${ }^{3}$ and \\ Jose O. Mora ${ }^{4}$
}

ABSTRACT

In 1996, the Honduran Ministry of Health conducted a national micronutrient survey of children 12-71 months old, which also included an assessment of the nutrition status of their mothers/caretakers. The 1126 mothers/caretakers who participated in the survey tended to be short and plump. About $15 \%$ of them were at obstetric risk by virtue of their short stature and/or low body weight. About $9 \%$ had chronic energy deficiency (CED), but $27 \%$ were at least $20 \%$ overweight. CED was associated with socioeconomic indicators of poverty. Risk factors for being at least $20 \%$ overweight included being over 30 years old, not breast-feeding, having attended no higher than grade 4, 5, or 6 of primary school, coming from a wealthier household, and living in San Pedro Sula or medium-sized cities. Among the women surveyed, $26 \%$ of nonpregnant and $32 \%$ of pregnant mothers/caretakers were anemic. The likely principal cause of anemia was the low intake of bioavailable iron from food and, in some cases, excessive iron loss associated with intestinal parasites, especially hookworm. Only 50\% of the mothers/caretakers participating in this study had received iron during their last pregnancy, and just $13 \%$ had received postpartum vitamin $A$. The results highlight the need to develop and implement an effective program to control iron deficiency anemia in women of reproductive age, including by fortifying such widely consumed foods as processed wheat and maize flour and by routinely administering iron supplements to high-risk groups. Postpartum vitamin A supplementation should be encouraged to protect both the mother and newborn infant against vitamin A deficiency.

Honduras is one of the poorest countries in Latin America and since the mid-1960s has been known to have one of the highest rates of child undernutrition in this region (1). Deficiencies of vitamin A and iodine, as well as iron deficiency anemia, have also been known to be significant public health problems

1 International Life Sciences Institute, Washington, D.C.

2 Honduras, Ministry of Health, Tegucigalpa, Honduras.

3 Mexico, National Institute of Nutrition. Mexico, D.F., Mexico

4 International Science and Technology Institute, Arlington, Virginia. Address correspondence to: Jose O. Mora, International Science and Technology Institute, 1820 North Fort Myer Drive, Suite 600, Arlington, VA 22209. Telephone: (703) 248-3312. Fax: (703) 807-0278. E-mail: jmora@istiinc.com for over three decades $(2,3)$. Nevertheless, as shown in another paper in this series (4), iodine deficiency has been largely controlled through universal salt iodization, and vitamin A deficiency has been significantly reduced as a result of both dietary and pharmaceutical interventions.

In contrast to the situation for children, the nutrition status of women has remained largely unknown, except for some data on iron deficiency anemia. For this reason, the 1996 National Micronutrient Survey included the collection of anthropometric measurements and the hemoglobin level of the mothers/caretakers of children 12-71 months old who were included in the survey.
Honduran women would be expected to show high levels of chronic malnutrition, with risks to their health and obstetric outcome, for a number of reasons. These include the longlasting effects of undernutrition in childhood on adult body size and a predominantly rural population (66\% in 1996) (5). Another factor is a fertility rate that is still high (4.5 in 1996), even following an average annual rate of reduction of $0.9 \%$ for $1960-1980$ and of $2.1 \%$ for 1980-1996 (5). Women of childbearing age are particularly vulnerable to malnutrition because of the nutritional costs associated with reproduction (pregnancy and lactation), on top of their everyday heavy workloads. Merchant and Martorell (6) 
have labeled the deleterious cumulative effect of repeated pregnancies on the nutrition status of mothers, above and beyond that caused by poverty, as the "maternal depletion syndrome." Women whose weight is below $40 \mathrm{~kg}$ are at high obstetric risk. Also at high risk are women whose height is below $145 \mathrm{~cm}$, because short stature is associated with small pelvic size and increased risk of maternal mortality. Stunting in adult women is also correlated with low birthweight infants, high risk of stillbirth, and a high rate of miscarriage (7). Another measure of nutrition status is the body mass index (BMI), which assesses thinness and obesity.

In this paper, basic anthropometric indicators for assessing the nutritional status of women are presented, and data on the association between nutritional status and anemia of nonpregnant mothers/caretakers and a number of nonbiological (geographic, social, and economic) and biological (agespecific and breast-feeding) factors are examined. These data are from the 1996 National Micronutrient Survey conducted on children 12-71 months old and their mothers/caretakers.

\section{METHODS}

The 1996 National Micronutrient Survey was conducted between July and October. Full details of the survey design and survey population will be published elsewhere (4). The survey consisted of a nationally representative sample of children 12-71 months old and their mothers or primary caretakers. Data were collected by three field teams, each having a supervisor, two phlebotomists, and two interviewers. Before the survey started, all field staff received two weeks of training, which included standardization of anthropometric measurements.

Data collected included standard household social and economic variables and use of iron and vitamin A supplements among mothers/caretakers. Mothers/caretakers were weighed on a bathroom scale calibrated daily to the nearest $0.5 \mathrm{~kg}$. Height was measured to the nearest $0.1 \mathrm{~cm}$ using a nonelastic tape measure suspended from a hook on a strip of wood placed vertically against a wall or door. The hook was placed so that the reading was " 0 " when the tape was fully extended. The strip of wood had hinges that allowed it to be folded, making it easy to transport. Weight, height, and body mass index (BMI) were used as indicators of maternal nutrition status.

Underweight women were those whose weight was less than $40 \mathrm{~kg}$, and stunted women were those whose height was below $145 \mathrm{~cm}$. Chronic energy deficiency (CED) was defined using the Quetelet body mass indices (BMI) (weight/height ${ }^{2}$ ) (8). In ideal reference populations for women, the normal range for the Quetelet BMI is between 21.5 and 23.1. Women who are $20 \%$ overweight have Quetelet BMIs between 25.8 and 27.3. Women who are severely overweight, that is, by $40 \%$ or more, have Quetelet BMIs between 30.1 and 32.3. At the other extreme, the International Dietary Energy Consultative Group (8) suggests that Quetelet BMIs between 17.0 and 18.5 are indicative of grade I (mild) CED, those between 16.0 and 17.0 of grade II (moderate) CED, and those below 16 of grade III (severe) CED. A Quetelet BMI of 12 is the absolute lower limit compatible with life.

Hemoglobin measurements were made on finger-prick blood samples from mothers/caretakers using a portable photometer (HemoCue, Angelholm, Sweden). Anemia was defined as having a hemoglobin $(\mathrm{Hb})$ level at sea level below $11 \mathrm{~g} / \mathrm{dL}$ in pregnant women and below $12 \mathrm{~g} / \mathrm{dL}$ in nonpregnant women (9). Hemoglobin levels were adjusted for altitude using the formula proposed by Yip ${ }^{5}$ : adjusted $\mathrm{Hb}$ $=\mathrm{Hb}-(-0.032 \times$ altitude $+0.022 \times$ altitude ${ }^{2}$ ), where altitude $=$ elevation in 1000 -foot units or in units of $1000 \mathrm{~m}$ $\times 3.3$.

\footnotetext{
5 Yip R. Altitude and hemoglobin elevations: implication for anemia screening and health risk of polycythemia. Paper presented at Eighth International Hypoxia Symposium, Hamilton, Ontario, 1993.
}

Data were entered in EPI INFO version 6 (U.S. Centers for Disease Control, Atlanta, Georgia) and exported to SPSS PC files, where analysis was done using SPSS for Windows version 5 (SPSS Inc., Chicago, Illinois). A probability level of less than 0.05 was used to define statistical significance. In the bivariate analyses, the sample was weighted by the normalized sample weights, which was the product of three numbers: the inverse of the sample weight, the household response rate, and the individual interview response rate. Sample sizes are presented as weighted observations. Logistic regression models were developed to predict low and high BMIs. In each model, the category in the bivariate analysis most positively associated with a low BMI or a high BMI was generally used as the reference category. The ratio of the odds in the logistic regressions have been transformed into the ratios of probabilities or relative risks for ease of understanding.

A technical committee that the Ministry of Health set up reviewed all documents and survey procedures. Written informed consent was obtained from all mothers/caretakers. Ethical approval for the survey was obtained from the Human Subjects Committee at Johns Hopkins University because this study's first author was an employee of the university at the time of the study.

\section{RESULTS}

Of the 2421 households visited, $96 \%$ agreed to participate in the survey but only $52 \%$ of the households were eligible, that is, had children $12-71$ months old. Among the eligible households, 94\% were successfully interviewed. Anthropometric and hemoglobin data were available for $97.8 \%$ of the mothers and $97.2 \%$ of the caretakers. Because data were collected on mothers/caretakers with children between 12 and 71 months old, the sample was biased towards women who were between 20 and 39 years old, the age interval in which women were most likely to 
TABLE 1. Mean and standard deviation (SD) height of all mothers/caretakers and weight and body mass index (BMI) of nonpregnant mothers/caretakers by background factors, Honduras, 1996

\begin{tabular}{|c|c|c|c|c|c|c|c|c|}
\hline & \multicolumn{3}{|c|}{ Height $(\mathrm{cm})$} & \multicolumn{2}{|c|}{ Weight (kg) } & \multicolumn{3}{|c|}{$\mathrm{BMI}^{\mathrm{a}}$} \\
\hline & Mean & SD & No. & Mean & SD & Mean & SD & No. \\
\hline \multicolumn{9}{|l|}{ Dominion } \\
\hline SPS $^{b}$ \& medium cities & 152.87 & 5.32 & 167 & 60.32 & 13.54 & 25.71 & 5.56 & 149 \\
\hline Other urban & 152.63 & 5.88 & 157 & 55.61 & 12.16 & 23.75 & 4.40 & 136 \\
\hline Rural north & 151.56 & 5.79 & 224 & 53.64 & 11.17 & 23.23 & 4.33 & 187 \\
\hline ANOVA & \multicolumn{3}{|c|}{$P<0.001$} & \multicolumn{2}{|c|}{$P<0.001$} & \multicolumn{3}{|c|}{$P<0.001$} \\
\hline \multicolumn{9}{|l|}{ Age group } \\
\hline$<20$ years & 150.92 & 5.84 & 87 & 48.88 & 8.26 & 21.47 & 2.86 & 49 \\
\hline 20-24 years & 152.17 & 6.23 & 240 & 52.35 & 10.67 & 22.49 & 4.28 & 192 \\
\hline $25-29$ years & 152.54 & 6.11 & 241 & 54.06 & 10.90 & 23.11 & 4.21 & 213 \\
\hline 30-34 years & 151.76 & 6.68 & 200 & 56.75 & 13.52 & 24.42 & 4.86 & 170 \\
\hline Yes & & & & 51.15 & 10.54 & 22.20 & 3.82 & 228 \\
\hline No & & & & 55.86 & 11.99 & 24.02 & 4.68 & 724 \\
\hline ANOVA & & & & \multicolumn{2}{|c|}{$P<0.001$} & & $P<0.001$ & \\
\hline Overall & 151.91 & 6.11 & 1126 & 54.76 & 11.36 & 23.60 & 4.43 & 962 \\
\hline
\end{tabular}

a $\mathrm{BMI}=$ weight $\div$ height ${ }^{2}$, where weight is given in kilograms and height is given in meters.

b SPS $=$ San Pedro Sula.

have a child within that age range (data not shown).

\section{Nutrition status of nonpregnant mothers/caretakers}

Table 1 shows the mean and standard deviation for height of all mothers/caretakers and mean and standard deviation for weight of nonpregnant Honduran mothers/caretakers. On average, mothers/caretakers were $152 \mathrm{~cm}$ tall (range 131 to $175 \mathrm{~cm}$ ) and weighed $55 \mathrm{~kg}$ (range 31.5 to $117 \mathrm{~kg}$ ). Mothers/caretakers in the rural west demographic/geographic "dominion"6 of

\footnotetext{
6 Dominions (dominios) are six demographic/ geographic groupings used by some ministries of the Government of Honduras. "Urban" dominions have more than 2000 inhabitants and are divided into the following three groupings: metropolitan Tegucigalpa; San Pedro Sula and "medium" cities-ones with a population between 20000 and 50000 - in any of the departments of the country; and "other" urban areas, ones with a population between 2000 and 20000 inhabitants, also in any department of the country. The three rural dominions-north, south, and west-match the political boundaries of departments but exclude all "urban" communities in their respective areas.
}

Honduras were $3.75 \mathrm{~cm}$ shorter than the average, while those in the rural south dominion were over $1.5 \mathrm{~cm}$ taller than the average. The age-based data suggest that Honduran women continued to grow in height until the age of 20 to 24 years.

Mothers/caretakers in the rural west weighed less than those in the other dominions. Mothers/caretakers weighed more in the dominion consisting of San Pedro Sula, the country's secondlargest city, and the "medium" cities, ones with a population between 20000 and 50000 . There was no association between mean weight and number of pregnancies.

Three percent of mothers/caretakers were both below $145 \mathrm{~cm}$ and $40 \mathrm{~kg}$ (i.e., at very high obstetric risk), 10\% were under $145 \mathrm{~cm}$ but heavier than $40 \mathrm{~kg}$ (i.e., at high obstetric risk), a further $2 \%$ were under $40 \mathrm{~kg}$ but taller than $145 \mathrm{~cm}$ (i.e., at high obstetric risk), and $85 \%$ were not at obstetric risk (Table 2). There was a higher proportion of mothers/caretakers in the rural west who were at obstetric risk, but the small number of cases in each category do not allow for meaningful statistical analysis.

Table 1 also shows that the mean Quetelet BMI for nonpregnant Honduran mothers/caretakers was 24, which was slightly above the normal range. Using the James et al. (8) classification, $8.6 \%$ of mothers/caretakers had chronic energy deficiency (CED), of which $6.4 \%$ had grade I CED, 1.5\% grade II CED, and $0.7 \%$ had grade III CED. Among mothers/caretakers, $26.8 \%$ were $20 \%$ or more overweight, including $8.6 \%$ who were more than $40 \%$ overweight.

A number of indicators reflecting a lower socioeconomic status were associated with low BMI. These included not having access to tap water, having no toilet, having a mud floor, and a "possession score" of zero, where one point each was given for owning a functioning radio, TV, refrigerator, stereo, electric iron, blender, or telephone (Table 3). None of the biological factors studied was associated with low BMI. The socioeconomic and health vari- 
TABLE 2. Percent distribution of nonpregnant mothers/caretakers at obstetric risk by dominion, Honduras, 1996

\begin{tabular}{lcccccc}
\hline & \multicolumn{5}{c}{ Obstetric risk $^{\mathrm{a}}$} \\
\cline { 2 - 5 } & $\begin{array}{c}\text { Very } \\
\text { high }^{\mathrm{b}}\end{array}$ & $\begin{array}{c}\text { High } \\
<145 \mathrm{~cm}\end{array}$ & $\begin{array}{c}\text { High } \\
<40 \mathrm{~kg}\end{array}$ & $\begin{array}{c}\text { Not } \\
\text { high }\end{array}$ & Total & Number \\
\hline Dominion & & & & & & \\
Tegucigalpa & 1.0 & 5.2 & 2.6 & 91.2 & 100.0 & 194 \\
SPSc \& medium cities & 1.2 & 5.4 & 0.6 & 92.8 & 100.0 & 167 \\
Other urban & 1.3 & 10.8 & 2.5 & 85.4 & 100.0 & 157 \\
Rural north & 3.1 & 9.8 & 1.8 & 85.3 & 100.0 & 224 \\
Rural west & 6.6 & 23.2 & 2.2 & 68.0 & 100.0 & 181 \\
Rural south & 3.0 & 4.9 & 2.5 & 89.7 & 100.0 & 203 \\
Overall & 2.8 & 9.8 & 2.0 & 85.4 & 100.0 & 1126 \\
\hline
\end{tabular}

${ }^{a}$ Cell sizes were too small for valid chi-square test.

${ }^{b}$ Very high $=$ both below $145 \mathrm{~cm}$ and $40 \mathrm{~kg}$.

c SPS = San Pedro Sula.
(Table 3). Overall, the risk of being overweight increased with age, but the differences in risk were not significant between mothers/caretakers under 20 years old and those in the 20-24 and 25-29 age groups. In contrast, the relative risk of a mother/ caretaker over the age of 30 being overweight was more than three times that of a mother/caretaker under 20 years old. Mothers/caretakers who were breast-feeding were $33 \%$ less likely to be overweight than those who were not breast-feeding, even after controlling for age. ables identified as important in the bivariate analyses were all associated with each other and overrode each other during development of the logistic regression model to determine their net effects on being underweight.

Being $20 \%$ or more overweight was associated with the dominion in which the mother/caretaker lived. Other indicators that reflected a higher social and economic status and that were associated with being overweight included being married or in an unmarried free union, having been to school, tap water in the house, a flush toilet, a tiled floor, and a possession score of 3 or more (Table 3). Among the biological variables, increased mother/caretaker age was positively associated with being $20 \%$ or more overweight up to the age range of 30 to 34 years, after which it plateaued. Breast-feeding was inversely related to being overweight. Although relatively few nonpregnant women had been dewormed in the preceding six months, there was a positive association between being $20 \%$ or more overweight and being dewormed.

The variables identified as important in the bivariate analyses were used in a logistic regression model to determine their net effects on being at least $20 \%$ overweight. The important determinants of mothers/caretakers in Honduras being overweight were age group, breast-feeding, level of education, possession score, and dominion
TABLE 3. Percent distribution of low body mass (BMI < 18.5) and percent distribution of high BMI (> 25.8) of nonpregnant mothers/caretakers by background factors and net relative risk of high BMI, Honduras, 1996

\begin{tabular}{|c|c|c|c|c|c|}
\hline & \multicolumn{2}{|c|}{ Low BMI } & \multicolumn{2}{|c|}{ High BMI } & \multirow{2}{*}{$\begin{array}{l}\text { Relative } \\
\text { risk } \\
\text { high BMI }\end{array}$} \\
\hline & $\%$ & No. & $\%$ & No. & \\
\hline \multicolumn{6}{|l|}{ Dominion } \\
\hline Tegucigalpa & & & 35.2 & 165 & $1.00^{\mathrm{a}}$ \\
\hline $\mathrm{SPS}^{b}$ \& medium cities & & & 45.0 & 149 & $1.34^{\mathrm{C}}$ \\
\hline Other urban & & & 27.2 & 136 & 0.84 \\
\hline Rural north & & & 26.2 & 187 & 1.12 \\
\hline Rural west & & & 12.2 & 147 & 0.68 \\
\hline Rural south & & & 16.3 & $\begin{array}{l}178 \\
P<0.001^{d}\end{array}$ & 0.74 \\
\hline \multicolumn{6}{|l|}{ Mother's age group $(y r)$} \\
\hline$<20$ & & & 10.2 & 49 & $1.00^{\mathrm{a}}$ \\
\hline $20-24$ & & & 15.1 & 192 & 1.46 \\
\hline $25-29$ & & & 22.1 & 213 & 2.07 \\
\hline $30-34$ & & & 34.1 & 170 & $3.48^{\mathrm{c}}$ \\
\hline $35-39$ & & & 34.7 & 147 & $3.72^{\mathrm{c}}$ \\
\hline$\geq 40$ & & & 35.6 & $\begin{array}{l}191 \\
P<0.001\end{array}$ & $3.66^{c}$ \\
\hline \multicolumn{6}{|l|}{ Mother's schooling } \\
\hline None & & & 16.5 & 164 & 0.92 \\
\hline Primary $1-3$ & & & 24.4 & 266 & 1.33 \\
\hline Primary 4-6 & & & 31.7 & 344 & $1.60^{c}$ \\
\hline Secondary $1+$ & & & 20.3 & $\begin{array}{l}188 \\
P<0.002\end{array}$ & $1.00^{\mathrm{a}}$ \\
\hline \multicolumn{6}{|l|}{ Marital status } \\
\hline Married & & & 31.6 & 323 & \\
\hline Free union & & & 25.3 & 434 & \\
\hline Not in union & & & 22.4 & $\begin{array}{l}205 \\
P<0.05\end{array}$ & \\
\hline \multicolumn{6}{|l|}{ Source of water } \\
\hline Tap in house & 5.9 & 187 & 42.8 & 187 & \\
\hline Tap in property & 6.7 & 476 & 28.2 & 476 & \\
\hline Public tap & 9.7 & 62 & 16.1 & 62 & \\
\hline River/stream/lake & 16.2 & 111 & 6.3 & 111 & \\
\hline Well with pump & 12.1 & 66 & 16.7 & 66 & \\
\hline Other & 13.3 & 60 & 26.7 & 60 & \\
\hline & \multicolumn{2}{|c|}{$P<0.02$} & \multicolumn{2}{|c|}{$P<0.001$} & \\
\hline
\end{tabular}


TABLE 3. (continued)

\begin{tabular}{|c|c|c|c|c|c|}
\hline & \multicolumn{2}{|c|}{ Low BMI } & \multicolumn{2}{|c|}{ High BMI } & \multirow{2}{*}{$\begin{array}{c}\text { Relative } \\
\text { risk } \\
\text { high BMl }\end{array}$} \\
\hline & $\%$ & No. & $\%$ & No. & \\
\hline \multicolumn{6}{|l|}{ Type of toilet } \\
\hline Flush & 6.0 & 298 & 39.9 & 298 & \\
\hline Outhouse & 7.4 & 163 & 25.8 & 163 & \\
\hline Pit latrine & 8.6 & 291 & 25.4 & 291 & \\
\hline \multirow[t]{2}{*}{ None } & 13.3 & 210 & 11.0 & 210 & \\
\hline & \multicolumn{2}{|c|}{$P<0.05$} & \multicolumn{2}{|c|}{$P<0.001$} & \\
\hline \multicolumn{6}{|l|}{ Type of floor } \\
\hline Mud & 11.0 & 436 & 15.4 & 436 & \\
\hline Cement tiles & 5.7 & 279 & 36.9 & 279 & \\
\hline \multirow[t]{2}{*}{ Mosaic tiles } & 7.7 & 247 & 35.6 & 247 & \\
\hline & \multicolumn{2}{|c|}{$P<0.05$} & \multicolumn{2}{|c|}{$P<0.001$} & \\
\hline \multicolumn{6}{|c|}{ Possession score } \\
\hline 0 & 13.9 & 237 & 11.0 & 237 & $0.29^{c}$ \\
\hline $1-2$ & 8.7 & 344 & 20.6 & 344 & $0.51^{c}$ \\
\hline $3-4$ & 5.6 & 196 & 36.7 & 196 & $0.77^{c}$ \\
\hline \multirow[t]{2}{*}{$5+$} & 4.9 & 185 & 48.1 & 185 & $1.00^{\mathrm{a}}$ \\
\hline & \multicolumn{2}{|c|}{$P<0.005$} & \multicolumn{2}{|c|}{$P<0.001$} & \\
\hline \multicolumn{6}{|c|}{ Currently breast-feeding } \\
\hline Yes & & & 16.7 & 228 & $0.67^{c}$ \\
\hline No & & & 29.8 & $\begin{array}{l}724 \\
P<0.001\end{array}$ & $1.00^{\mathrm{a}}$ \\
\hline \multicolumn{6}{|c|}{ Antihelminth last 6 months } \\
\hline Yes & & & 36.8 & 114 & \\
\hline No & & & 25.4 & $\begin{array}{l}846 \\
P<0.01\end{array}$ & \\
\hline Overall & 8.6 & 962 & 26.8 & 962 & 952 \\
\hline
\end{tabular}

Compared with mothers/caretakers who had attended at least grade 1 of secondary school, mothers who had gone no further than grade 4, 5 , or 6 of primary school were $60 \%$ more likely to be overweight. The household possession score, which was a proxy for wealth, also predicted mothers/caretakers being overweight. Mothers/caretakers from households that had fewer than five of the possessions that were counted were between $30 \%$ and $80 \%$ less likely to be overweight than those from households with five or more of the possessions. In terms of dominion, mothers/caretakers in San Pedro Sula and medium cities were about $35 \%$ more likely to be overweight than those in Tegucigalpa, but there was no difference in the risk of being overweight between the other dominions and Tegucigalpa.

\section{Iron supplements}

Mothers/caretakers were asked whether they had been given ironcontaining supplements during their last pregnancy and in the preceding six months. Overall, $49 \%$ of all respondents had received iron supplements in their last pregnancy (Table 4) and $19 \%$ had received them within the last six months. More of the mothers/ caretakers who had received iron in the preceding six months were pregnant $(46.1 \%$ versus $16.0 \%, P<0.001)$. Mothers/caretakers under 40 years of age were more likely to have received iron supplements during their last pregnancy; that was also true for mothers/caretakers with more years of education (Table 4).

Overall, $69 \%$ of mothers/caretakers had obtained their last supply of supplements from a government health worker (Table 4). With the exception of mothers/caretakers in San Pedro Sula and medium cities, the majority of mothers/caretakers in the other dominions obtained these supplements from a government health worker; this was especially true in the rural west. More mothers/caretakers in San Pedro Sula and medium cities got their supplements from a private health worker than in the other dominions (Table 4). Among mothers/caretakers who received iron supplements during their last pregnancy, there was no association between the source of the supplements and age. More mothers/caretakers who had been to secondary school obtained their supplements from a private health worker.

Eighty-eight percent of the iron supplements given to pregnant mothers/caretakers were tablets, of which $52 \%$ were prenatal vitamin-mineral or ferrous sulfate supplements (data not shown).

\section{Antihelminths}

Overall, $11 \%$ of mothers/caretakers were dewormed during their last pregnancy. More mothers/caretakers 35-39 years of age and more mothers/caretakers who had attended at least grade 
TABLE 4. Percentage of mothers/caretakers who received iron during the last pregnancy, percent distribution source of iron in last pregnancy, and percentage who received antihelminth in preceding six months by dominion, age group, and schooling, Honduras, 1996

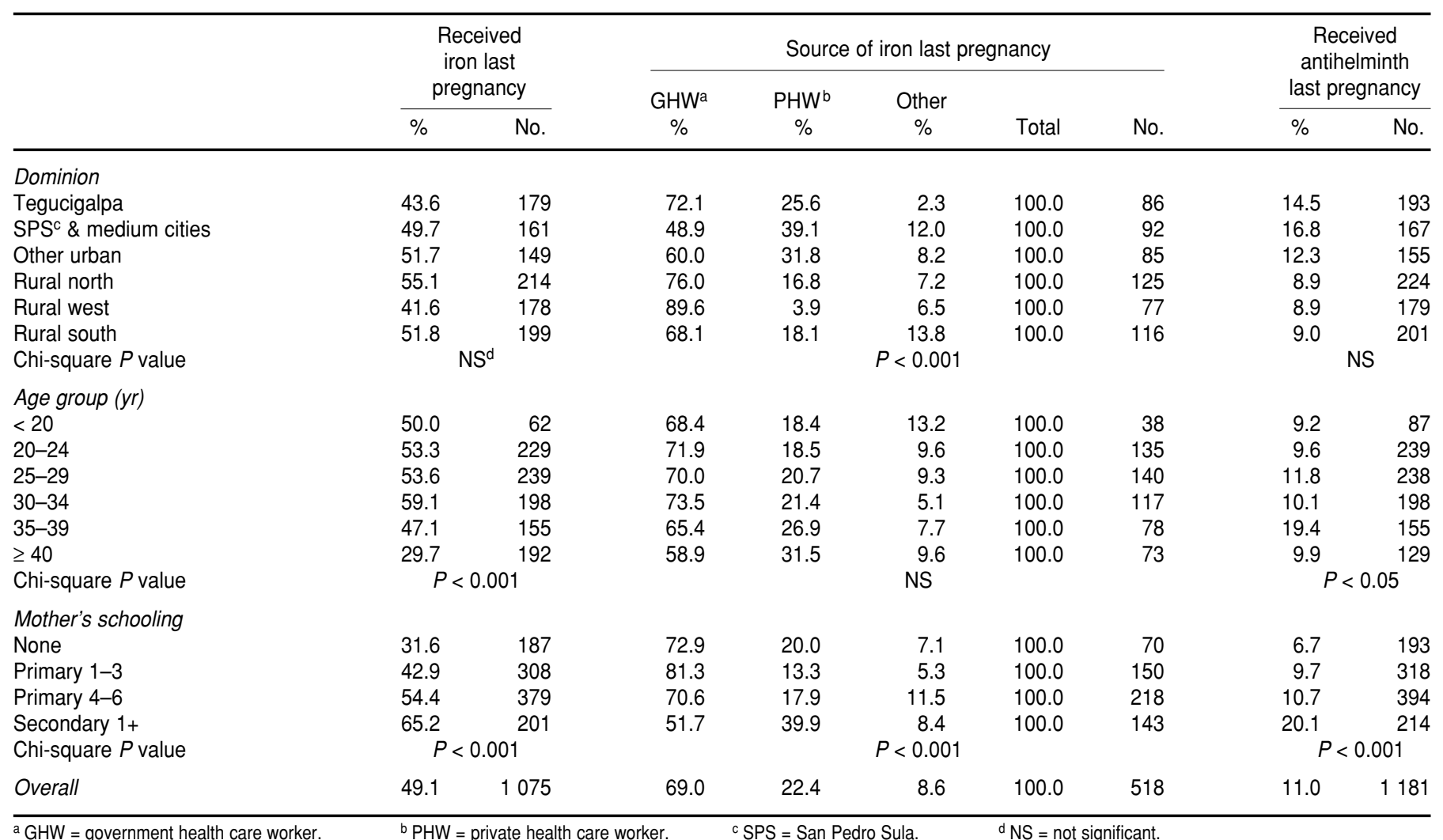

1 of secondary school had been dewormed than other mothers/caretakers (Table 4).

\section{Vitamin A supplements}

Fewer than $15 \%$ of mothers/caretakers had received vitamin $\mathrm{A}$ after the birth of their last child, and there were no differences between the dominions in having received postpartum vitamin A. There was, however, an inverse association between receiving postpartum vitamin $\mathrm{A}$ and increasing age (Table 5). In $88 \%$ of the cases where the mothers/caretakers had received postpartum vitamin $\mathrm{A}$, the supplement had come from a health worker (data not shown).

\section{DISCUSSION}

In general, Honduran mothers/ caretakers tended to be short and plump, which could be a function of their having been chronically undernourished in childhood and/or it may be genetically related. For example, the short-stature Lenca ethnic group is dominant in the rural west, where average height is the lowest.

Compared with regional-level data for women 15 to 49 years old in Latin America (1), women in this survey were $0.5 \mathrm{~cm}$ shorter, which probably explains the slightly higher $(2 \%)$ proportion that were under $145 \mathrm{~cm}$ in height. Overall, women in this survey were $2.7 \mathrm{~kg}$ lighter and had a BMI 1.1 lower that the regional averages. Applying the definition of James et al. (8), the proportion of mothers/caretakers who had CED in Honduras was 9.0\%, compared with the regional average of $7.2 \%$ for women of reproductive age. The CED in Honduras was associated only with poverty, using possession score, source of water, type of toilet, and type of floor as proxies for wealth. Using the cutoff points cited in Kra- sovec and Anderson (7), about $15 \%$ of mothers/caretakers in this survey were at obstetric risk by virtue of their short stature and/or low body weight.

Of the mothers/caretakers who were surveyed, $27 \%$ of them were $20 \%$ or more overweight and 9\% were more than $40 \%$ overweight. The risk factors for being at least $20 \%$ overweight included being over 30 years old, not currently breast-feeding, having attended only up to grade 4,5 , or 6 of primary school, coming from a household with a greater number of possessions, and living in San Pedro Sula and medium cities. Clinical and epidemiological studies have shown that women tend to gain weight through middle age $(10,11)$. Breast-feeding mobilizes energy reserves laid down before and during pregnancy (12). The risk of being overweight most likely reflects the social and cultural complexity of education attainment, perceptions of physical appearance, and income level. By itself, living in a par- 
TABLE 5. Percentage of mothers/caretakers who received vitamin A after their last birth, by age group, Honduras, 1996

\begin{tabular}{lcr}
\hline & \multicolumn{2}{c}{$\begin{array}{c}\text { Received } \\
\text { postpartum } \\
\text { vitamin A }\end{array}$} \\
\cline { 2 - 3 } Age group $(\mathrm{yr})$ & $\%$ & No. \\
\hline$<20$ & 15.5 & 58 \\
$20-24$ & 18.3 & 229 \\
$25-29$ & 15.5 & 232 \\
$30-34$ & 13.0 & 193 \\
$35-39$ & 8.5 & 153 \\
$40+$ & 4.2 & 190 \\
Chi-square $P$ value & \multicolumn{2}{c}{$P<0.001$} \\
Overall & 12.6 & 1055 \\
\hline
\end{tabular}

ticular dominion does not cause overweight. Therefore, dominion must have been acting as a proxy for other factors that are associated with nutrition but that were not measured in the National Micronutrient Survey, such as access to and use of food.

The findings on the nutrition status of Honduran mothers/caretakers show quite clearly that overnutrition is more of a health risk than undernutrition. While problems associated with overweight among adult women-including diabetes, hypertension, and coronary heart disease-may be of more concern to the health authorities than undernutrition, the plight of poor mothers/caretakers should not be overlooked.

Anemia among women of reproductive age was both highly prevalent and widespread, affecting close to one in four nonpregnant and one in three pregnant mothers/caretakers. Given the relatively small sample size of pregnant mothers/caretakers, the results for this group need to be interpreted with caution. Of the biological and nonbiological factors investigated, only pregnancy was associated with anemia. This suggests that the low bioavailability of dietary iron and possibly high hookworm level are most likely to be the underlying causes of anemia. Data on those two conditions were not collected in the survey, and there are no other national data available on the prevalence of hookworm infestation in the country. Intake of bioavailable iron is low, largely because most of the iron is derived from plant sources and consumption of iron absorption inhibitors, notably coffee, is high while that of iron absorption enhancers is low (13).

Only one-half of the mothers/caretakers participating in this study had received iron during their last pregnancy. Women under the age of 40 were more likely to have received iron supplements than older women. Receiving iron supplements was positively associated with increased educational level of the mother/caretaker. This was probably due to the income effect associated with being better educated-and therefore being able to afford better antenatal care-and/or the effect of education per se. The results indicate that more attention needs to be given to educating health professionals about the need for iron supplements. This will ensure that pregnant women receive iron-containing supplements, as well as counseling on issues related to taking them. The public at large also need to be better informed about anemia so that women will be aware of the need to prevent anemia, especially during pregnancy. The problems of the poorest and most vulnerable women have to continue being addressed and the State must have a more effective role in securing a more effective supply of iron supplements for women of reproductive age, especially during pregnancy. This would imply rationalizing the distribution of prenatal supplements, including by using normal private sector marketing channels.

Antihelminths have been shown to be safe in reducing the prevalence of anemia in pregnant women (14). However, unless hookworm infestations are known to exist, routine deworming of pregnant women would not be necessary. In addition, health care workers in Honduras advise women to limit the use of medication during pregnancy, which could have led to the low number of mothers/caretakers who received an antihelminth in their last pregnancy. The association between having received an antihelminth in the last pregnancy and education level could have been due to the income effect associated with better schooling and/or the effect of schooling per se.

About one in eight mothers/caretakers had received postpartum vita$\min \mathrm{A}$. The fact that more younger women had been given a vitamin A capsule after delivery reflects the relatively new policy of providing women with vitamin A soon after they give birth. Even so, the data suggest that more attention needs to be given to educating health professionals about the protective effect of postpartum vitamin A supplements against vitamin A deficiency in both the mother and newborn infant.

The results presented in this paper raise some important reproductive health program issues, including the need to develop and implement an effective program to control iron deficiency anemia in women of reproductive age. The essential components of this program are fortification of such widely consumed foods as processed wheat and maize flour, the routine administration of iron/folate supplements to pregnant women, and highdose postpartum vitamin A supplementation. If a high prevalence of intestinal parasites-especially hookworm-is found, then consideration should also be given to periodic deworming of groups at high risk of helminth infestation.

Acknowledgments. The survey was implemented in collaboration with the International Eye Foundation. Technical and financial assistance was provided through the Opportunities for Micronutrient Interventions (OMNI) Project, funded by Contract Number HRN-C-00-93-00025-08 of the U.S. Agency for International Development. Thanks are due to the field teams and households who made the survey possible and to Dr. Frances Davidson, of A.I.D./Washington, for his support and helpful comments. 


\section{REFERENCES}

1. United Nations, Administrative Committee on Coordination/Sub-Committee on Nutrition. Second report on the world nutrition situation: volume II country trends, methods, and statistics. Geneva: UN; 1993.

2. Interdepartmental Committee for National Defense/Instituto de Nutrición de Centro América y Panamá. Nutritional evaluation of the population of Central America and Panama. Washington, D.C.: U.S. Department of Health, Education, and Welfare; 1972. (DHEW Publication No. HSM72-8120).

3. Daza CH. Deficiencias vitamínicas en América Latina y el Caribe. In: Rozo C, Mamone M, eds. Vitaminas: agentes nutritivos y terapéuticos. Barcelona: Ediciones Doyma. 1986. pp. 1-10.

4. Nestel P, Mellara A, Rosado J, Mora JO. Undernutrition among Honduran children 12 through 71 months of age. Rev Panam Salud Publica. Forthcoming 1999.

5. United Nation's Children's Fund. State of the world's children. New York: UNICEF; 1998.
6. Merchant K, Martorell R. Frequent reproductive cycling: Does it lead to nutrition depletion of mothers? Prog Food Nutr Sci. 1988;12 (4):339-369.

7. Krasovec K, Anderson M. Maternal nutrition and pregnancy outcomes: anthropometric assessment. Washington, D.C.: PAHO; 1991. (PAHO Scientific Publication 259).

8. James WPT, Ferro-Luzzi A, Waterlow JC. 1988. Definition of chronic energy deficiency in adults. Report of a working party of the International Dietary Energy Consultative Group. Eurp J Clin Nutr 42(12):969-981.

9. World Health Organization. Nutritional anemia. Geneva: WHO; 1972. (WHO Technical Report Series No. 3).

10. Kuczmarksi R. Need for body composition information in the elderly. Am J Clin Nutr 1989 Nov;50(5 Suppl):1150-1157.

11. Williamson DF, Khan HS, Remington PL, Anda RF. The 10-year incidence of overweight and major weight gain in US adults. Arch Intern Med 1990 Mar;150(3):665-672.
12. Whitehead RG, ed. Maternal diet, breast-feeding capacity, and lactational infertility. Tokyo: United Nations University Press; 1981. (Publication WHTR-5/UNUP-338).

13. Rogers B, Swindale A, Ohri-Vachaspati P. Determinants of household food security in Honduras: a report on the national household consumption, income, expenditure, and nutrition survey, 1993-1994. Washington, D.C. U.S. Agency for International Development/ IMPACT Project; 1996.

14. Atukorala TM, de Silva LD, Dechering WH, Dassenaeike TS, Perera RS. Evaluation of effectiveness of iron-folate supplementation and antihelminthic therapy against anemia in pregnancy-a study in the plantation sector of Sri Lanka. Am J Clin Nutr 1994 Aug;60 (2):286-292.

Manuscript received on 14 March 1998. Accepted for publication on 19 January 1999.

RESUMEN En 1996, el Ministerio de Salud de Honduras realizó una encuesta nacional sobre los micronutrientes en niños de 12 a 71 meses de edad, en la cual también se evaluó el estado nutricional de las madres o guardianas. Las 1126 madres o guardianas que participaron en la encuesta mostraron la tendencia a ser de estatura baja y a tener un exceso de peso. Alrededor de $15 \%$ eran de riesgo obstétrico elevado debido a su baja estatura, su poco peso corporal, o ambas cosas. Cerca de $9 \%$ tenían deficiencia energética crónica (DEC), pero $27 \%$ tenían un sobrepeso mínimo de $20 \%$. La DEC se asoció con indicadores socioeconómicos de pobreza. Entre los factores de riesgo de tener un sobrepeso mínimo de 20\% figuraron tener más de 30 años de edad, no haber amamantado, no haber cursado más allá de cuarto, quinto o sexto año de primaria, venir de un hogar más próspero, y vivir en San Pedro Sula o en una ciudad de tamaño mediano. De las mujeres encuestadas, $26 \%$ de las madres y guardianas no embarazadas y $32 \%$ de las embarazadas tenían anemia. La causa más probable de la afección fue la poca ingestión de hierro biodisponible en los alimentos y, en algunos casos, la pérdida excesiva de hierro ocasionada por la parasitosis intestinal, especialmente la anquilistomiasis. Solamente $50 \%$ de las madres o guardianas que participaron en el estudio habían recibido hierro durante el embarazo previo, y apenas $13 \%$ habían recibido vitamina A después del parto. Los resultados subrayan la necesidad de crear y poner en marcha un programa eficaz para controlar la anemia por deficiencia de hierro en mujeres de edad reproductiva aplicando determinadas medidas, entre ellas la fortificación de alimentos de consumo general, como las harinas procesadas a base de trigo y maíz, y la administración periódica de suplementos de hierro a grupos de alto riesgo. La suplementación con vitamina A después del parto debe fomentarse con el fin de proteger a la madre y al recién nacido de la deficiencia de esta vitamina. 